\title{
A Brief Overview of Nutrient Anti-Inflammatory Molecules and their In Vitro and In Vivo Activity
}

\author{
Elaine Wei Ting Lim ${ }^{1}$, Steven T Leach ${ }^{1 *}$, Daniel A Lemberg ${ }^{1,2}$ and Andrew S Day ${ }^{3}$ \\ ${ }^{1}$ School of Women's and Children's Health, University of New South Wales, Sydney, Australia \\ ${ }^{2}$ Department of Paediatric Gastroenterology, Sydney Children's Hospital, Sydney, Australia \\ ${ }^{3}$ Department of Paediatrics, University of Otago, New Zealand
}

*Corresponding author: Dr. Steven T Leach, BSc (Hons) PhD, School of Women's and Children's Health, University of New South Wales, Sydney, Australia, Tel: +61 (2) 9382 1883, Fax: +61 (2) 9382 1574, E-mail: s.leach@unsw.edu.au

\begin{abstract}
Anti-inflammatory nutrients are components of normal dietary intake with reported anti-inflammatory properties. In comparison to traditional pharmacological anti-inflammatory drugs, antiinflammatory nutrients may have lower side effects. However, one limitation of anti-inflammatory nutrients is their inefficiency compared to current pharmacological anti-inflammatory drugs as higher nutrient concentrations may be required to provide similar pharmacological effect. A large range of anti-inflammatory nutrients are currently under investigation for their therapeutic use and efficacy: these include amino acids, fats, vitamins and flavonoids. This review provides a brief overall perspective of the existing literature on anti-inflammatory nutrients and their proposed mechanisms of action.
\end{abstract}

\section{Introduction}

Inflammatory responses are the basic mechanisms of the immune system against microbial invasion as well as promoting healing. Inflammation is described as the local response to cellular injury that is marked by capillary dilatation, leukocytic infiltration, redness, heat, pain, swelling and sometimes loss of function due to pro-inflammatory mediators [1]. Although inflammation is part of a normal response to tissue injury, when uncontrolled, it results in earlier development of chronic diseases such as asthma, rheumatoid arthritis, multiple sclerosis, hepatitis, ulcerative colitis and Crohn's disease [2]. Chronic inflammation also contributes to the development of cancer, cardiovascular diseases and neurodegenerative diseases [35]. Chronic diseases are the leading causes of fatal burden of disease, disability and death in Australia, accounting for up to $90 \%$ of all deaths in 2011 [6]. Current pharmacological therapies to control chronic inflammatory disease have the potential for undesirable side effects. Therefore, there is potential for new therapies to be used longterm with minimal negative effects to control chronic inflammatory disease.

Anti-inflammatory nutrients are components of normal dietary intake with reported anti-inflammatory properties. Compared to traditional pharmacological anti-inflammatory drugs, antiinflammatory nutrients may have less side effects [7]. There is a large range of anti-inflammatory nutrients that are currently beginning to be investigated for their therapeutic use and efficacy in a range of diseases including chronic inflammatory disease. The most prominent nutrient molecules with reported in vitro and/ or in vivo anti-inflammatory propertied include; amino acids, fats, vitamins and flavonoids. The aim of this review is to provide a brief overall perspective of the existing literature on these reported antiinflammatory nutrients and their proposed mechanisms of action with a focus of these agents in gut inflammation.

\section{Inflammatory Pathways}

There are many biological mediators involved in the inflammatory cascade and anti-inflammatory agents act by inhibiting synthesis or action of these mediators. The inflammatory pathway that is stimulated is often dependent on the type of pathogen introduced to the system. For example, bacterial pathogens are recognised by tolllike receptors (TLRs) and trigger a distinctly different response to viral infections that trigger type 1 interferons (IFN) through a TLR independent mechanism [8].

However, the nuclear factor (NF)- $\kappa \mathrm{B}$ pathway unites inflammatory and metabolic responses and directs the body's inflammatory response by controlling the expression of genes involved in inflammation. In the (NF)- $\mathrm{BB}$ canonical pathway, triggered by TLRs and pro-inflammatory cytokines, ligand-receptor

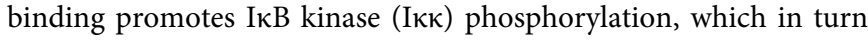
promoted I $\kappa \mathrm{B}$ degradation and release of NF- $\kappa \mathrm{B}$ [9]. The free NF$\kappa \mathrm{B}$ dimer complexes are then translocated to the nucleus to bind to specific DNA sequences to promote transcription of inflammatory mediators [10]. The NF- $\kappa \mathrm{B}$ pathway is central to inflammation and therefore is generally the target of a number of anti-inflammatory therapies.

Peroxisome proliferator-activator receptors (PPARs) play an important role in regulating inflammatory response through transactivation and transrepression of NF- $\mathrm{KB}$ and AP1 signalling pathways, suppressing expression of pro-inflammatory mediators including inducible nitric oxide synthase (iNOS) and interleukins [11], therefore are also key to anti-inflammatory responses.

\section{Amino Acids}

Amino acids are organic compounds that are biologically essential for life and are required for synthesis of proteins and other biomolecules. The two main types of amino acids in human nutrition 
are essential and non-essential amino acids and are classified depending on whether the body is able to synthesise them from other compounds for normal growth. Some amino acids have been found to exhibit anti-inflammatory properties through suppression of inflammatory mediators in the inflammatory cascade [12-15].

\section{Glutamine}

Glutamine is a non-essential amino acid under normal physiological conditions that is used in the biosynthesis of proteins. Glutamine is the most abundant amino acid in the body and plasma [16]. Glutamine is a precursor for purines, pyrimidines and amino acid synthesis and acts as a nitrogen shuttle between tissues $[17,18]$. The rate of skeletal muscle protein synthesis is directly related to the intracellular glutamine concentration [19]. Additionally, glutamine is an energy source for some cell types such as enterocytes and lymphocytes [18]. Glutamine exerts an anti-inflammatory effect through attenuating pro-inflammatory cytokine and chemokine production [12]. This is achieved with higher nutrient concentrations

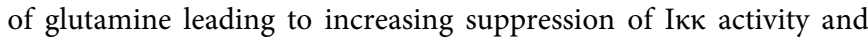
reduction of IKB degradation [12]. Glutamine is reported to block phosphorylation of NF- $\mathrm{KB}$ signalling components as well as the signalling components in $\mathrm{P} 38$ mitogen-activated protein kinase (MAPK) pathway in TNF- $\alpha$ exposed HT-29 cells $[12,20]$.

\section{Arginine}

Arginine is a non-essential amino acid under normal physiological conditions. Arginine acts as a substrate for protein, creatinine and polyamine synthesis as well as production of nitric oxide through the deiminase pathway [21]. Arginine has similar anti-inflammatory properties to glutamine in that it attenuates chemokine response of IL-8 production in TNF- $\alpha$ exposed HT-29 cells and decreases

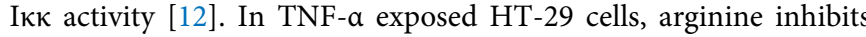
phosphorylation of signalling components of the NF- KB and MAPK pathways $[12,20]$.

\section{Cysteine}

Cysteine is a non-essential amino acid for adults but may be essential in infants and the elderly or in individuals with certain metabolic diseases or malabsorption syndromes [22]. Although cysteine is one of the least abundant amino acids in the body, it is required in functionally important sites of proteins including the catalytic, regulatory and cofactor binding sites [23]. Cysteine has been observed to inhibit chemokine IL-8 response in the human monocytic leukaemia cell line, THP-1 cells and peripheral blood mononuclear cells (PCMC) stimulated with TNF- $\alpha$ [13]. Cysteine also reduces activation of NF- $\kappa B$ in THP- 1 cells stimulated with TNF- $\alpha$ [13].

\section{Histidine}

Histidine is considered an essential amino acid required in protein biosynthesis for growth and tissue repair. Histidine is metabolised to histamine, which has been described as an antiinflammatory agent [24]. Histidine exerts its anti-inflammatory properties through affecting chemokine IL- 8 response in THP-1 cells and PCMC stimulated with TNF- $\alpha$ [13]. In addition, histidine also inhibits production of TNF- $\alpha$ and IL- 6 in lipopolysaccharide (LPS)-induced mouse peritoneal macrophages in a concentrationdependent manner. This activity is specific to the L-histidine isomer as $\mathrm{D}$-histidine and the histidine metabolite carnosine had no such antiinflammatory effect [14]. Histidine also reduces NF- $\kappa B$ activation in THP- 1 cells stimulated with TNF- $\alpha$ [13]. Histidine has been shown to inhibit LPS-induced NF- $\kappa B$ activation in macrophages [14]. Histidine also inhibits expression of intracellular adhesion molecule-1 (ICAM1, CD54) in THP-1 cells and PBMCs [13].

\section{Glycine}

Glycine is a non-essential amino acid and is an important component and precursor for many macromolecules in the cells. Glycine is found primarily in gelatine and silk fibroin and used therapeutically as a nutrient. Glycine has been reported to show anti-inflammatory properties through reduced activation of NF- $\kappa \mathrm{B}$ in THP-1 cells stimulated with TNF- $\alpha$ [13]. Dietary glycine has been shown to significantly inhibit the increase of IL- $1 \beta$ and TNF- $\alpha$ in two experimental colitis models (2,4,6-trinitrobenzene sulphonic acid (TNBS) and dextran sulfate sodium (DSS) rat models) [15]. Glycine also abrogates TNBS induction of cytokine-induced neutrophil chemoattractant and macrophage inflammatory protein (MIP)-2 in the colonic tissue [15].

\section{Selenocysteine}

Selenocysteine is a non-essential, naturally occurring amino acid found in transfer RNAs and catalytic site of some enzymes. Selenocysteine is considered the $21^{\text {st }}$ amino acid as the selenium analogue of cysteine, where selenium replaces the sulphur atom [25]. Selenium must be included in the dietary intake to meet required levels of Selenocysteine for normal immune function [26]. Epidemiological studies have suggested an inverse association between selenium levels and inflammatory bowel disease (IBD), which includes Crohn's disease and ulcerative colitis [27]. Selenium has been shown to down regulate NF- $\kappa B$ dependent thromboxane synthase, microsomal prostaglandin and $\mathrm{PGE}_{2}$ synthase pathways, which catalyse the conversion of $\mathrm{PGH}_{2}$ to $\mathrm{PGE}_{2}$ and also aids in the eicosanoid class-switching phenomenon to differentially regulate inflammatory pathways $[28,29]$. Selenium and selenoprotein expression in macrophages inhibit the NF- $\kappa \mathrm{B}$ pathway through a covalent adduct formation of IкB kinase- 2 with 15-Deoxy- $\Delta^{12,14}$-prostaglandin $\mathrm{J}_{2}\left(15 \mathrm{~d}-\mathrm{PG} \mathrm{J}_{2}\right)$ [30]. Further, dietary selenium regulates prostaglandins promoting resolution and reduces reactive oxygen species. The composition of the gut microbiota is also affected by the presence of dietary selenium [27].

\section{Tryptophan}

Tryptophan is an essential amino acid required for normal growth in infants and for nitrogen balance in adults. Tryptophan is a precursor of serotonin, a neurotransmitter essential in regulating appetite, mood, sleep and pain [31]. Tryptophan is present in dairy products, meat, brown rice, fish and soybeans. Kynurenic acid, a product of the normal metabolism of tryptophan, targets the N-methyl-D-aspartate receptors of the enteric nervous system [32]. Kynurenic acid is able to suppress TNF- $\alpha$ and IL-6 levels after TNBS administration in a mouse colitis model, and it also decreases myeloperoxidase (MPO) activity significantly in the large bowel [33].

\section{$\gamma$-glutamyl}

$\gamma$-glutamyl is a functional group that can be added to individual amino acid molecules to form dipeptides such as $\gamma$-glutamyl cysteine and $\gamma$-glutamyl valine through a reaction with $\gamma$-glutamyl Cysteine synthetase [34]. $\gamma$-glutamyl is able to inhibit TNF- $\alpha$ signalling in intestinal epithelial cells and reduce inflammation in DSS-induced colitis through reduced production of IL-8, IL- 6 and IL- $1 \beta$, and through allosteric activation of the calcium-sensing receptor in the gastrointestinal tract [35].

\section{Fats (Triglycerides)}

There are three generic types of triglycerides; unsaturated, saturated and trans. Unsaturated triglycerides are liquid in room temperature and considered to be beneficial in improving cholesterol levels and reducing inflammation [36].

\section{Omega-3 fatty acids}

Omega-3 fatty acids, also known as n-3 polyunsaturated fatty acids (PUFAs), includes eicosapentaenoic and docosahexaenoic acids which are mainly found in fish oil [37]. Consumption of fish oils diminishes lymphocyte proliferation, T-cell-mediated cytotoxicity, natural killer cell activity, macrophage-mediated cytotoxicity, monocyte and neutrophil chemotaxis, major histocompatibility class (MHC) II expression and antigen presentation, and production of pro-inflammatory cytokines IL-1, IL-6 and TNF- $\alpha$ [38,39].

Another type of omega- 3 fatty acids is $\alpha$-linolenic acid, which is mainly found in plant oils such as linseed oil and green plant tissues [38]. Diets containing large amounts of $\alpha$-linolenic acid have been 
shown to reduce lymphocyte proliferation compared to saturated fatty acid or n-6 PUFA-rich diets [38]. Most vegetable oils are rich in n-6 PUFA linoleic acid, the precursor of arachidonic acid, which lead to increased synthesis of pro-inflammatory mediators such as prostaglandins, leukotrienes and thromboxane [38]. However linoleic acid, $a$-linolenic acid, docosahexaenoic acid (DHA) and eicosapentaenoic acid (EPA) reduce IL-6, IL-1 $\beta$ and TNF- $\alpha$ gene expression in LPS stimulated THP-1 cells $[40,41]$. Therefore, the antiinflammatory properties of these types of fats are not immediately clear.

There are at least two mechanistic theories to explain the beneficial effects of n-3 PUFA on inflammation; eicosanoid suppression [38,42] and PPAR activation [43]. N-3 fatty acids from fish oil inhibit cytokine and eicosanoid formation by competing with n-6 fatty acids for incorporation in cell phospholipids and for the binding sites of cyclooxygenase and lipoxygenase [44-47]. Populations consuming a diet low in arachidonic acid (less than $90 \mathrm{mg}$ /day) have been shown to have lower inflammatory rates of rheumatoid arthritis (RA) compared to populations consuming a normal Western diet $[48,49]$ In addition, patients on low arachidonic acid diet supplemented with fish oil capsules, had the least clinical sign of inflammation $[48,50]$.

\section{Conjugated linoleic acid}

Conjugated linoleic acid (CLA) induce both PPAR- $\gamma$ and $\delta$ by modulating PPAR- $\gamma$ and $\delta$-responsive gene clusters which are involved in lipid metabolism and epithelial cell maturation [51]. CLA also suppresses TNF- $\alpha$ expression and NF- $\kappa B$ activation while inducing the immune-regulatory cytokine transforming growth factor $\beta 1$ in DSS induced colitis [52]. Removal of the PPAR- $\gamma$ gene in the colon abrogated the beneficial effects of CLA in DSS colitis thus indicating that CLA ameliorates colitis through a PPAR- $\gamma$-dependent mechanism [51].

\section{Vitamins}

Vitamins are organic components in the diet that are required for growth and maintenance of normal physiological functioning. Vitamins are separated into fat-soluble vitamins such as vitamin A, D, $\mathrm{E}$, and $\mathrm{K}$ or water-soluble vitamins such as vitamin $\mathrm{B}_{12}, \mathrm{~B}_{6}$, and $\mathrm{C}$ [53].

\section{Vitamin A}

Vitamin A is essential for proper retinal functioning, differentiation and growth of tissue, bone health, reproduction and the immune response [53]. Low vitamin A levels have been associated with increased chronic bacterial infections, splenomegaly and high neopterin levels indicating a more active inflammatory response [54]. Vitamin A deficient non-colitic rats have been shown to have higher plasma malondialdehyde concentration compared to vitamin A-sufficient and vitamin A-supplemented non-colitic rats, indicating increased oxidative stress in vitamin A deficiency [55]. Vitamin A also inhibits translocation of transcription factor NF- $\kappa B$ and interrupting the secretion of inflammatory cytokines [56]. Vitamin A supplementation in deficient patients have also shown to increase IL-10 and decrease TNF- $\alpha$ levels [57].

\section{Vitamin D}

Vitamin D, which includes calciferol and cholecalciferol, is found in liver tissue and fish oils and is essential for calcium absorption [58]. Vitamin D serum concentration has been found to be associated with disease severity in IBD $[47,59]$. The health benefits of 1,25-dihydroxycholecalciferol seem to be exclusively mediated by vitamin D receptors [59,60]. Calcitriol, the hormonally active form of vitamin $\mathrm{D}$ exerts its anti-inflammatory actions through suppression of prostaglandin, inhibition of both p38 MAPK and NF- $\mathrm{kB}$ signalling pathway in lymphocytes, fibroblast and peripheral blood monocytes [61-65]. In addition, vitamin D suppresses the production of proinflammatory cytokines such as TNF- $\alpha$ [65].

\section{Vitamin E}

Vitamin E includes tocopherols and tocotrienols, with $\alpha$ and $\gamma$-tocopherol being the two major forms found in some fruits, vegetables, plant seeds and nuts [66,67]. Although both exhibit similar anti-inflammatory actions, $\gamma$-tocopherols shown to be more potent than $\alpha$-tocopherol in inhibiting the cyclooxygenase pathway in macrophages, reducing the production of inflammatory mediators such as $\mathrm{PGE}_{2}$ as well as suppressing the action of reactive nitrogen species [68-70]. A specific a-tocopherol metabolite, 2,5,7,8-tetramethyl-2-(b-carboxyethyl)-6-hydroxychroman (a-CEHC) has anti-inflammatory properties, mediated through suppression of TNF- $\alpha$ and LPS-stimulated nitrite and $\mathrm{PGE}_{2}$ production. A further metabolite, 2,7,8-trimethyl-2- (b-carboxyethyl) -6-hydroxychroman only suppresses LPS-stimulated nitrite and $\mathrm{PGE}_{2}$ production [71]. Vitamin $\mathrm{E}$ and $\mathrm{C}$ also help to lower free radical plasma concentrations with the combined administration of these vitamins resulting in reduced TNF- $\alpha$ levels [72].

\section{Flavonoids}

Flavonoids are polyphenolic compounds which includes flavonols, flavonones, flavanols, flavans and isoflavans: these are naturally present in vegetables, fruits and plant derivatives such as wine [73].

\section{Citrus flavonoids}

The anti-inflammatory properties of the citrus flavonoids, hesperidin, and its flavone analogue, diosmin, have been studied. Diosmin and hesperidin inhibit the synthesis and biological activities of different pro-inflammatory mediators, mainly the arachidonic acid derivatives, prostaglandins E2 and F2 and thromboxane A2 [74-76]. Biosynthesis of the inflammatory arachidonic acid-derived mediators involves the actions of phospholipase A2 and key oxidative enzymes, such as cyclooxygenase and lipoxygenase [77]. Flavonoid inhibition of inflammatory reactions catalysed by phospholipase A2, cyclooxygenase and lipoxygenase in vitro, prevents neutrophil activation and the production of reactive oxygen species at inflammation sites [77].

\section{Apigenin}

Apigenin, found in celery and parsley, has been shown to have anti-inflammatory properties. Apigenin suppresses the expression of IL- 8 , IL- $1 \beta$ and TNF- $\alpha$ in LPS-stimulated mouse macrophage and human monocytes [78,79]. Apigenin has also been shown to suppress NF- $\kappa B$ activity and inhibit cyclooxygenase- 2 and iNOS expression in LPS-stimulated mouse macrophages [80].

\section{Baicalein}

Baicalein flavone, originally isolated from Scutellaria baicalensis roots is noted to have anti-inflammatory activities. Baicalein inhibits iNOS, cyclooxygenase-2, TNF- $\alpha$ expression and suppresses NF- $\kappa B$ activation in LPS induced RAW264.7 cells [81].

\section{Genistein}

Genistein, found in soy beans and soy bean-related products, has similar anti-inflammatory properties to other flavonoids. Genistein suppresses the expression of IL-6, IL- $1 \beta$ and TNF- $\alpha$ in LPS stimulated mouse macrophages [82]. It also inhibitsSTAT-1, NF- $\kappa$ B activity, cyclooxygenase- 2 and iNOS expression in LPS-stimulated mouse macrophages $[80,83]$.

\section{Other Nutrients}

\section{Curcumin}

Curcumin is the main yellow pigment found in turmeric and it is a widely used spice and food colouring agent [84]. Studies have shown that curcumin could play a protective role in ulcerative colitis through regulation of oxidant and anti-oxidant balance as well as controlled release of inflammatory mediators such as TNF- $\alpha$ and nitric oxide [85].

Curcumin significantly attenuates intestinal damage associated with IBD as well as reducing MPO activity and TNF- $\alpha$ release [86]. 
Table 1: Summary of nutrient anti-inflammatory concentrations.

\begin{tabular}{|c|c|c|c|c|}
\hline Nutrient & Concentration/ Dose & Delivery method & Cell/ Animal type & Ref. \\
\hline \multicolumn{5}{|l|}{ Amino Acids } \\
\hline Glutamine & $15-240 \mathrm{mM}$ & in vitro & HT29 cells & [12] \\
\hline Arginine & $2.5-50 \mathrm{mM}$ & in vitro & HT29 cells & [12] \\
\hline Cysteine & $0.2-20 \mathrm{mM}$ & in vitro & THP-1 cells & [13] \\
\hline \multirow[t]{2}{*}{ Histidine } & $20 \mathrm{mM}$ & in vitro & THP-1 cells & [13] \\
\hline & $626 \mathrm{mg}$ & Oral, in vivo & SCID mice & [14] \\
\hline \multirow[t]{2}{*}{ Glycine } & $20 \mathrm{mM}$ & in vitro & THP-1 cells & [13] \\
\hline & $50 \mathrm{~g} / \mathrm{kg}$ & Oral, in vivo & Wistar rats & [15] \\
\hline Selenium/ Selenocysteine & 0.4-1.0 ppm & Oral, in vivo & C57BL/6 mice & [29] \\
\hline Kynurenic acid & $25 \mathrm{mg} / \mathrm{kg}$ & IV, in vivo & Sprague-Dawley rats & [33] \\
\hline \multirow[t]{2}{*}{ V-glutamyl cysteine and Y-glutamyl valine } & $0.5 \mathrm{mM}$ & in vitro & Caco- 2 cells & [35] \\
\hline & $150 \mathrm{mg} / \mathrm{kg}$ & Oral, in vivo & BALB/c mice & [35] \\
\hline \multicolumn{5}{|l|}{ FATS } \\
\hline Eicosapentaenoic acids & $100 \mu \mathrm{M}$ & in vitro & THP-1 cells & {$[41]$} \\
\hline a-linolenic acid & $100 \mu \mathrm{M}$ & in vitro & THP-1 cells & {$[40]$} \\
\hline Conjugated linoleic acid & $45-80 \mathrm{mg} / \mathrm{day}$ & Oral, in vivo & C57BL6/J mice & [51] \\
\hline \multicolumn{5}{|l|}{ Vitamins } \\
\hline Vitamin A & $41 \mathrm{IU} / \mathrm{kg} /$ day & Oral, in vivo & Sprague-Dawley rats & {$[56]$} \\
\hline Vitamin D & 50 IU/day & Oral, in vivo & C57BL/6 mice & [59] \\
\hline \multirow[t]{2}{*}{ Vitamin E } & 800 mg/day & Oral, in vivo & Human & [65] \\
\hline & 500 ppm & Oral, in vivo & Mice & [65] \\
\hline \multicolumn{5}{|l|}{ Flavonoids } \\
\hline \multirow[t]{2}{*}{ Citrus flavonoids (Hesperidin and Diosmin) } & 500 mg Daflon & in vitro & Endothelial fibroblasts, RBL-2H3 cells & {$[75,76]$} \\
\hline & 100 mg/d Daflon & $\mathrm{SC}$, in vivo & Rats & [76] \\
\hline \multirow[t]{2}{*}{ Apigenin } & $10-30 \mu \mathrm{M}$ & in vivo & J773.2 cells, RAW 264.7 cells & {$[78,79]$} \\
\hline & $50 \mathrm{mg} / \mathrm{kg}$ & IV, in vitro & C57BL/6J mice & [79] \\
\hline Baicalein & $10 \mu \mathrm{M}$ & in vitro & RAW264.7 cells & [81] \\
\hline Genistein & $10-100 \mu \mathrm{M}$ & in vitro & J774 cells & [83] \\
\hline \multicolumn{5}{|l|}{ Others } \\
\hline S-allyl cysteine & $80 \mathrm{mg} / \mathrm{kg}$ & Oral, in vivo & Rats & [101] \\
\hline
\end{tabular}

Curcumin also reduced colonic nitrite levels and induced downregulation of cyclooxygenase- 2 and iNOS expression, as well as a reduction in the activation of p38 MAPK signalling pathway [86]. The inhibition of p38 MAPK signalling pathway by curcumin could result in the reduction in cyclooxygenase- 2 and iNOS inflammatory mediators and suppress the colonic mucosa nitrite production, thus reducing the development of chronic colitis in experimental animals [86]. Curcumin has also been shown to activate PPAR- $\gamma$ and its ligands in TNBS-induced colitis in rats through inhibition of NF- $\kappa B$ translocation [87]. In addition, curcumin has been shown to suppress NF- $\mathrm{kB}$ and AP-1 in human glioma cells and inhibit expression of proinflammatory cytokines in murine lymphocytes and macrophages [88-92].

Pro-inflammatory molecules inhibited by curcumin include phospholipase, lipooxygenase, cyclooxygenase 2, leukotrienes, thromboxane, prostaglandins, nitric oxide, collagenase, elastase, hyaluronidase, monocyte chemoattractant protein-1 (MCP-1), interferon-inducible protein, TNF- $\alpha$, and IL-12 [93]. In addition, in vitro studies have shown that the curcumin analogue, 2,6-bis (3,4-dihydroxybenzylidene) cyclohexanone, has a stronger inhibitory effect on the growth of the mouse macrophage cell line RAW264.7, compared to curcumin [94]. Further, this curcumin analogue was able to suppress 12-O-tetra-decanoylphorbol-13-acetate (TPA)induced increases in NF- $\mathrm{\kappa B}$ activation and IL- $1 \beta$ expression more effectively than curcumin [94]. In vivo studies also indicate that the analogue was better than curcumin in the inhibition of mouse ear oedema and IL- $1 \beta$ production induced by TPA [94].

Curcumin has been demonstrated to be anti-inflammatory and to be safe in six human trials [93]. Therefore, curcumin appears to be a very promising therapeutic agentto treat inflammatory diseases.

\section{Resveratrol}

Resveratrol is a phytoalexin, a protective antibiotic produced by plants under stress, and it is found in grapes, red wine, mulberries, pines, peanuts and other plant-derived products [95]. Resveratrol exhibits anti-inflammatory properties through inhibition of the NF$\kappa B$ pathway in macrophages, splenocytes and myeloid cells [96-98]. Furthermore, it prevents cyclooxygenase- 2 and iNOS production in human primary airway epithelial cells and suppresses nitric oxide and TNF- $\alpha$ as well as other cytokines from macrophages and microglial cells $[78,99,100]$.

\section{S-allyl cysteine (SAC)}

S-allyl cysteine (SAC) is the most abundant organosulfur compound in aged garlic extracts (AGE) [101]. SAC exerts antiinflammatory actions through inhibition of TLR4 and Iкא activity, and increasing the PPAR- $\gamma$ expression which has the overall effect of decreasing NF- $\mathrm{kB}$ pathway signalling. SAC also results in reduced levels of pro-inflammatory cytokines such as IL-1 $\beta$ [101] (Table 1).

\section{Conclusion}

There is a significant volume of literature reporting the antiinflammatory activities of numerous nutrients. A number of amino acids, and their derivatives, have been reported to exert antiinflammatory effects through suppression of inflammatory pathways and reduced production of anti-inflammatory mediators. Omega-3 fatty acids such as DHA, EPA as well as linoleic acid and conjugated linoleic acid, reduce inflammation and promote protective effects by suppressing synthesis of pro-inflammatory mediators. Vitamins are important for normal physiological processes in the human body but also appear to be increasingly important in the suppression and control of inflammation. Flavonoids have many anti-inflammatory properties: several are currently being investigated for their therapeutic action as they are able to suppress the production of inflammatory mediators through major inflammatory pathways.

The possibility of using nutrients instead of synthetically derived 
anti-inflammatory drugs is very promising however there remains concern around the effective concentrations required for nutrient anti-inflammatory benefits. Understanding of how nutrients exert anti-inflammatory effects will assist in the development of safer and potentially more effective anti-inflammatory therapies. Nevertheless, there appears to be a role for these nutrients in future therapeutic interventions for chronic inflammatory disease.

\section{References}

1. Rankin JA (2004) Biological mediators of acute inflammation. AACN Clin Issues15: 3-17.

2. Serhan CN, Ward PA, Gilroy DW (2010) Fundamentals of Inflammation. Yale J Biol Med 84: 64-65.

3. Coussens LM, Werb Z (2002) Inflammation and cancer. Nature 420: 860-867.

4. Libby P, Ridker PM, Maseri A (2002) Inflammation and atherosclerosis. Circulation 105: 1135-1143.

5. Wyss-Coray T, Mucke L (2002) Inflammation in neurodegenerative disease-a double-edged sword. Neuron 35: 419-432.

6. Australian Institute of Health and Welfare (2014) Australia's health 2014 Australia's health series no. 14, Canberra.

7. Bacchi S, Palumbo P, Sponta A, Coppolino MF (2012) Clinical Pharmacology of Non-Steroidal Anti-Inflammatory Drugs: A Review. Antiinflamm Antiallergy Agents Med Chem 11: 52-64.

8. Medzhitov R (2010) Inflammation 2010: New Adventures of an Old Flame. Cell 140: 771-776.

9. Lawrence T (2009) The Nuclear Factor NF-kB Pathway in Inflammation. Cold Spring Harb Perspect Biol 1: a001651.

10. Hayden MS, Ghosh S (2008) Shared Principles in NF-kB Signaling. Cell 132 344-362.

11. Daynes RA, Jones DC (2002) Emerging roles of PPARS in inflammation and immunity. Nat Rev Immunol 2: 748-759.

12. Alhagamhmad MH, Day AS, Lemberg DA, Leach ST (2016) Exploring and Enhancing the Anti-Inflammatory Properties of Polymeric Formula. JPEN J Parenter Enteral Nutr.

13. Hasegawa S, Ichiyama T, Sonaka I, Ohsaki A, Hirano R, et al. (2011) Amino acids exhibit anti-inflammatory effects in human monocytic leukemia cell line, THP-1 cells. Inflamm Res 60: 1013-1019.

14. Andou A, Hisamatsu T, Okamoto S, Chinen H, Kamada N, et al. (2009) Dietary Histidine Ameliorates Murine Colitis by Inhibition of Proinflammatory Cytokine Production From Macrophages. Gastroenterology 136: 564-574.

15. Tsune I, Ikejima K, Hirose M, Yoshikawa M, Enomoto N, et al. (2003) Dietary glycine prevents chemical-induced experimental colitis in the rat. Gastroenterology 125: 775-785

16. Scalise M, Pochini L, Galluccio M, Indiveri C (2016) Glutamine transport. From energy supply to sensing and beyond. Biochim Biophys Acta 1857 1147-1157.

17. Newsholme P, Lima MM, Procopio J, Pithon-Curi TC, Doi SQ, et al. (2003) Glutamine and glutamate as vital metabolites. Braz J Med Biol Res 36: 153163.

18. Miller AL (1999) Therapeutic considerations of L-glutamine: a review of the literature. Altern Med Rev 4: 239-248.

19. Mittendorfer B, Volpi E, Wolfe RR (2001) Whole body and skeletal muscle glutamine metabolism in healthy subjects. Am J Physiol Endocrinol Metab 280: E323-E333.

20. Rapin JR, Wiernsperger N (2010) Possible Links between Intestinal Permeablity and Food Processing: A Potential Therapeutic Niche fo Glutamine. Clinics 65: 635-643.

21. Morris SM (2006) Arginine: beyond protein. Am J Clin Nutr 83: 508s-512s.

22. Bishop ML, Fody EP, Schoeff LE (2013) Clinical Chemistry: Principles, Techniques, and Correlations. Lippincott Williams \& Wilkins.

23. Marino SM, Gladyshev VN (2012) Analysis and Functional Prediction of Reactive Cysteine Residues. J Biol Chem 287: 4419-4425.

24. Grohmann U, Bronte V (2010) Control of immune response by amino acid metabolism. Immunol Rev 236: 243-264.

25. Johansson L, Gafvelin GE, Arnér ES (2005) Selenocysteine in proteinsproperties and biotechnological use. Biochim Biophys Acta 1726: 1-13.

26. Brown KM, Arthur JR (2001) Selenium, selenoproteins and human health: a review. Public Health Nutr 4: 593-599.

27. Kudva AK, Shay AE, Prabhu KS (2015) Selenium and inflammatory bowel disease. Am J Physiol Gastrointest Liver Physiol 309: G71-G77.
28. Gandhi UH, Kaushal N, Ravindra KC, Hegde S, Nelson SM, et al. (2011) Selenoprotein-dependent up-regulation of hematopoietic prostaglandin D2 synthase in macrophages is mediated through the activation of peroxisome proliferator-activated receptor (PPAR) gamma. J Biol Chem 286: 27471 27482

29. Kaushal N, Kudva AK, Patterson AD, Chiaro C, Kennett MJ, et al. (2014) Crucial role of macrophage selenoproteins in experimental colitis. J Immuno 193: 3683-3692.

30. Vunta H, Davis F, Palempalli UD, Bhat D, Arner RJ, et al. (2007) The antiinflammatory effects of selenium are mediated through 15-deoxy-Delta12, 14-prostaglandin J2 in macrophages. J Biol Chem 282: 17964-17973.

31. Birdsall TC (1998) 5-Hydroxytryptophan: a clinically-effective serotonin precursor. Altern Med Rev 3: 271-280.

32. Davies NW, Guillemin G, Brew BJ (2010) Tryptophan, Neurodegeneration and HIV-Associated Neurocognitive Disorder. Int J Tryptophan Res 3: 121140

33. Érces D, Varga G, Fazekas B, Kovács T, Tőkés T, et al. (2012) N-methyld-aspartate receptor antagonist therapy suppresses colon motility and inflammatory activation six days after the onset of experimental colitis in rats. Eur J Pharmacol 691: 225-234.

34. Orlowski M, Meister A (1971) Partial Reactions Catalyzed by Y-Glutamylcysteine Synthetase and Evidence for an Activated Glutamate Intermediate. Journal of Biological Chemistry 246: 7095-7105.

35. Zhang H, Kovacs-Nolan J, Kodera T, Eto Y, Mine Y (2015) Y-Glutamyl cysteine and $y$-glutamyl valine inhibit TNF- $\alpha$ signaling in intestinal epithelial cells and reduce inflammation in a mouse model of colitis via allosteric activation of the calcium-sensing receptor. Biochim Biophys Acta 1852: 792-804.

36. Appel LJ, Sacks FM, Carey VJ, Obarzanek E, Swain JF, et al. (2005) Effects of protein, monounsaturated fat, and carbohydrate intake on blood pressure and serum lipids: results of the OmniHeart randomized trial. JAMA 294: 24552464.

37. Roche HM, Gibney MJ (2000) Effect of long-chain n-3 polyunsaturated fatty acids on fasting and postprandial triacylglycerol metabolism. Am J Clin Nutr 71: 232s-7s.

38. Calder PC (1998) Immunoregulatory and anti-inflammatory effects of n-3 polyunsaturated fatty acids. Braz J Med Biol Res 31: 467-490.

39. Wall R, Ross RP, Fitzgerald GF, Stanton C (2010) Fatty acids from fish: the anti-inflammatory potential of long-chain omega-3 fatty acids. Nutr Rev 68: 280-289.

40. Zhao G, Etherton TD, Martin KR, Vanden Heuvel JP, Gillies PJ, et al. (2005) Anti-inflammatory effects of polyunsaturated fatty acids in THP-1 cells. Biochem Biophys Res Commun 336: 909-917.

41. Weldon SM, Mullen AC, Loscher CE, Hurley LA, Roche HM (2007) Docosahexaenoic acid induces an anti-inflammatory profile in lipopolysaccharide-stimulated human THP-1 macrophages more effectively than eicosapentaenoic acid. J Nutr Biochem 18: 250-258.

42. Calder PC (1998) Dietary Fatty Acids and the Immune System. Nutr Rev 56 S70-S83.

43. Diep QN, Touyz RM, Schiffrin EL (2000) Docosahexaenoic acid, a peroxisome proliferator-activated receptor- $\alpha$ ligand, induces apoptosis in vascular smooth muscle cells by stimulation of p38 mitogen-activated protein kinase. Hypertension 36: 851-855.

44. Cleland LG, James MJ, Neumann MA, D'Angelo M, Gibson RA (1992) Linoleate inhibits EPA incorporation from dietary fish-oil supplements in human subjects. Am J Clin Nutr 55: 395-399.

45. Whelan J (1996) Antagonistic effects of dietary arachidonic acid and n-3 polyunsaturated fatty acids. J Nutr 126: 1086S-1091S.

46. Espersen GT, Grunnet N, Lervang HH, Nielsen GL, Thomsen BS, et al. (1992) Decreased Interleukin-1 beta levels in plasma from rheumatoid arthritis patients after dietary supplementation with $n-3$ polyunsaturated fatty acids. Clin Rheumatol 11: 393-395.

47. Geerling BJ, Badart-Smook A, van Deursen C, van Houwelingen AC, Russel MG, et al. (2000) Nutritional supplementation with N-3 fatty acids and antioxidants in patients with Crohn's disease in remission: Effects on antioxidant status and fatty acid profile. Inflamm Bowel Dis 6: 77-84.

48. Adam O, Beringer C, Kless T, Lemmen C, Adam A, et al. (2003) Antiinflammatory effects of a low arachidonic acid diet and fish oil in patients with rheumatoid arthritis. Rheumatol Int 23: 27-36.

49. Phinney SD, Odin RS, Johnson SB, Holman RT (1990) Reduced arachidonate in serum phospholipids and cholesteryl esters associated with vegetarian diets in humans. Am J Clin Nutr 51: 385-392.

50. Whelan J, Surette ME, Hardardóttir I, Lu G, Golemboski KA, et al. (1993) Dietary arachidonate enhances tissue arachidonate levels and eicosanoid production in Syrian hamsters. J Nutr 123: 2174-2185. 
51. Bassaganya-Riera J, Reynolds K, Martino-Catt S, Cui Y, Hennighausen L, et al (2004) Activation of PPAR $y$ and $\delta$ by conjugated linoleic acid mediates protection from experimental inflammatory bowel disease. Gastroenterology 127: 777-791.

52. Viladomiu M, Hontecillas R, Yuan L, Lu P, Bassaganya-Riera J (2013) Nutritional protective mechanisms against gut inflammation. J Nutr Biochem 24: 929-939.

53. Bender DA (2003) Nutritional biochemistry of the vitamins. ( $2^{\text {nd }}$ edn), Cambridge university press.

54. Cunningham-Rundles S, Cervia JS (1996) Malnutrition and host defense Nutrition in pediatrics: basic science and clinical application. ( $2^{\text {nd }}$ edn) Switzerland, 295-307.

55. Reifen R, Nur T, Ghebermeskel K, Zaiger G, Urizky R, et al. (2002) Vitamin A deficiency exacerbates inflammation in a rat model of colitis through activation of nuclear factor-kappaB and collagen formation. J Nutr 132: 2743-2747.

56. Horton JW, White DJ, Maass DL, Hybki DP, Haudek S, et al. (2001) Antioxidant vitamin therapy alters burn trauma-mediated cardiac NF-kappaB activation and cardiomyocyte cytokine secretion. J Trauma 50: 397-406.

57. Aukrust P, Müller F, Ueland T, Svardal AM, Berge RK, et al. (2000) Decreased vitamin A levels in common variable immunodeficiency: vitamin A supplementation in vivo enhances immunoglobulin production and downregulates inflammatory responses. Eur J Clin Invest 30: 252-259.

58. Ross AC, Taylor CL, Yaktine AL, Del Valle HB (2011) Dietary reference intakes for calcium and vitamin D. National Academies Press

59. Cantorna MT, Munsick C, Bemiss C, Mahon BD (2000) 1 25-Dihydroxycholecalciferol prevents and ameliorates symptoms of experimental murine inflammatory bowel disease. J Nutr 130: 2648-2652.

60. Veldman CM, Cantorna MT, DeLuca HF (2000) Expression of 1 25-Dihydroxyvitamin D3 Receptor in the Immune System. Arch Biochem Biophys 374: 334-338.

61. Moreno J, Krishnan AV, Swami S, Nonn L, Peehl DM, et al. (2005) Regulation of prostaglandin metabolism by calcitriol attenuates growth stimulation in prostate cancer cells. Cancer Res 65: 7917-7925.

62. Nonn L, Peng L, Feldman D, Peehl DM (2006) Inhibition of p38 by vitamin D reduces interleukin-6 production in normal prostate cells via mitogenactivated protein kinase phosphatase 5: implications for prostate cancer prevention by vitamin D. Cancer Res 66: 4516-4524.

63. Yu XP, Bellido T, Manolagas SC (1995) Down-regulation of NF-kappa B protein levels in activated human lymphocytes by 1,25-dihydroxyvitamin D3. Proc Natl Acad Sci U S A 92: 10990-10994.

64. Harant H, Wolff B, Lindley IJ (1998) 1a, 25-dihydroxyvitamin D 3 decreases DNA binding of nuclear factor-KB in human fibroblasts. FEBS Lett 436: 329-334.

65. Stio M, Martinesi M, Bruni S, Treves C, Mathieu C, et al. (2007) The Vitamin $\mathrm{D}$ analogue TX 527 blocks NF-kB activation in peripheral blood mononuclea cells of patients with Crohn's disease. J Steroid Biochem Mol Biol 103: 51-60.

66. Reiter E, Jiang Q, Christen S (2007) Anti-inflammatory properties of $\alpha$ - and Y-tocopherol. Mol Aspects Med 28: 668-691.

67. Jiang Q (2014) Natural forms of vitamin E: metabolism, antioxidant, and antiinflammatory activities and their role in disease prevention and therapy. Free Radic Biol Med 72: 76-90.

68. Funk CD (2001) Prostaglandins and leukotrienes: Advances in eicosanoid biology. Science 294: 1871-1875

69. Cooney RV, Franke AA, Harwood PJ, Hatch-Pigott V, Custer LJ, et al. (1993) Gamma-tocopherol detoxification of nitrogen dioxide: superiority to alphatocopherol. Proc Natl Acad Sci U S A 90: 1771-1775

70. Christen S, Woodall AA, Shigenaga MK, Southwell-Keely PT, Duncan MW et al. (1997) $y$-Tocopherol traps mutagenic electrophiles such as $\mathrm{NO}(\mathrm{x})$ and complements a-tocopherol: Physiologicalimplications. Proc Natl Acad Sci U S A 94: 3217-3222.

71. Grammas P, Hamdheydari L, Benaksas EJ, Mou S, Pye QN, et al. (2004) Anti-inflammatory effects of tocopherol metabolites. Biochem Biophys Res Commun 319: 1047-1052.

72. Rizzo MR, Abbatecola AM, Barbieri M, Vietri MT, Cioffi M, et al. (2008) Evidence for Anti-Inflammatory Effects of Combined Administration of Vitamin $E$ and $C$ in Older Persons with Impaired Fasting Glucose: Impact on Insulin Action. J Am Coll Nutr 27: 505-511.

73. Manach C, Scalbert A, Morand C, Rémésy C, Jiménez L (2004) Polyphenols: food sources and bioavailability. Am J Clin Nutr 79: 727-747.

74. Benavente-García O, Castillo J (2008) Update on Uses and Properties of Citrus Flavonoids: New Findings in Anticancer, Cardiovascular, and Antiinflammatory Activity. J Agric Food Chem 56: 6185-6205.

75. Damon M, Flandre O, Michel F, Perdrix L, Labrid C, et al. (1987) Effect of chronic treatment with a purified flavonoid fraction on inflammatory granuloma in the rat. Study of prostaglandin E2 and F2 alpha and thromboxane B2 release and histological changes. Arzneimittelforschung 37: 1149-1153.
76. Lerond L (1994) Action of Dation $500 \mathrm{mg}$ on the Principal Inflammatory Mediators. Phlebology 9: 34-39.

77. Manthey JA, Grohmann K, Guthrie N (2001) Biological Properties of Citrus Flavonoids Pertaining to Cancer and Inflammation. Curr Med Chem 8: 135153.

78. Kowalski J, Samojedny A, Paul M, Pietsz G, Wilczok T (2005) Effect of apigenin, kaempferol and resveratrol on the expression of interleukin-1beta and tumor necrosis factor-alpha genes in J774.2 macrophages. Pharmacol Rep 57: 390-394.

79. Nicholas C, Batra S, Vargo MA, Voss OH, Gavrilin MA, et al. (2007) Apigenin blocks lipopolysaccharide-induced lethality in vivo and proinflammatory cytokines expression by inactivating NF-kappaB through the suppression of p65 phosphorylation. J Immunol 179: 7121-7127.

80. Liang YC, Huang YT, Tsai SH, Lin-Shiau SY, Chen CF, et al. (1999) Suppression of inducible cyclooxygenase and inducible nitric oxide synthase by apigenin and related flavonoids in mouse macrophages. Carcinogenesis 20: $1945-1952$

81. Fan GW, Zhang Y, Jiang X, Zhu Y, Wang B, et al. (2013) Anti-inflammatory Activity of Baicalein in LPS-Stimulated RAW264.7 Macrophages via Estrogen Receptor and NF-[kappa]B-Dependent Pathways. Inflammation 36: 15841591.

82. Calixto JB, Campos MM, Otuki MF, Santos AR (2004) Anti-inflammatory compounds of plant origin. Part II. modulation of pro-inflammatory cytokines, chemokines and adhesion molecules. Planta Med 70: 93-103.

83. Hämäläinen M, Nieminen R, Vuorela P, Heinonen M, Moilanen E (2007) Anti-Inflammatory Effects of Flavonoids: Genistein, Kaempferol, Quercetin and Daidzein Inhibit STAT-1 and NF-kB Activations, Whereas Flavone, Isorhamnetin, Naringenin, and Pelargonidin Inhibit only NF-kB Activation along with Their Inhibitory Effect on iNOS Expression and NO Production in Activated Macrophages. Mediators Inflamm 2007: 45673.

84. Ramírez-Tortosa MC, Mesa MD, Aguilera MC, Quiles JL, Baró L et al. (1999) Oral administration of a turmeric extract inhibits LDL oxidation and has hypocholesterolemic effects in rabbits with experimental atherosclerosis. Atherosclerosis 147: 371-378.

85. Arafa HM, Hemeida RA, El-Bahrawy Al, Hamada FM (2009) Prophylactic role of curcumin in dextran sulfate sodium (DSS)-induced ulcerative colitis murine model. Food Chem Toxicol 47: 1311-1317.

86. Camacho-Barquero L, Villegas I, Sánchez-Calvo JM, Talero E, SánchezFidalgo S, et al. (2007) Curcumin, a Curcuma longa constituent, acts on MAPK p38 pathway modulating COX-2 and iNOS expression in chronic experimental colitis. Int Immunopharmacol 7: 333-342.

87. Zhang M, Deng C, Zheng J, Xia J, Sheng D (2006) Curcumin inhibits trinitrobenzene sulphonic acid-induced colitis in rats by activation of peroxisome proliferator-activated receptor gamma. Int Immunopharmacol 6: 1233-1242.

88. Dhandapani KM, Mahesh VB, Brann DW (2007) Curcumin suppresses growth and chemoresistance of human glioblastoma cells via AP-1 and NFkappaB transcription factors. J Neurochem 102: 522-538.

89. Gao X, Kuo J, Jiang H, Deeb D, Liu Y, et al. (2004) Immunomodulatory activity of curcumin: suppression of lymphocyte proliferation, development of cell-mediated cytotoxicity, and cytokine production in vitro. Biochem Pharmacol 68: 51-61.

90. Singh S, Aggarwal BB (1995) Activation of transcription factor NF-kappa B is suppressed by curcumin diferuloylmethane [corrected]. J Biol Chem 270 : 24995-5000.

91. Aggarwal S, Ichikawa H, Takada Y, Sandur SK, Shishodia S, et al. (2006) Curcumin (diferuloylmethane) down-regulates expression of cell proliferation and antiapoptotic and metastatic gene products through suppression of IkappaBalpha kinase and Akt activation. Mol Pharmacol 69: 195-206.

92. Shishodia S, Amin HM, Lai R, Aggarwal BB (2005) Curcumin (diferuloylmethane) inhibits constitutive NF-kappaB activation, induces G1/S arrest, suppresses proliferation, and induces apoptosis in mantle cell lymphoma. Biochem Pharmacol 70: 700-713

93. Chainani-Wu N (2003) Safety and anti-inflammatory activity of curcumin: a component of tumeric (Curcuma longa). J Altern Complement Med 9: 161168.

94. Du ZY, Wei X, Huang MT, Zheng X, Liu Y, et al. (2013) Anti-proliferative, antiinflammatory and antioxidant effects of curcumin analogue A2. Arch Pharm Res 36: 1204-1210.

95. Gehm BD, McAndrews JM, Chien PY, Jameson JL (1997) Resveratrol, a polyphenolic compound found in grapes and wine, is an agonist for the estrogen receptor. Proc Natl Acad Sci U S A 94: 14138-14143.

96. Gao X, Xu YX, Janakiraman N, Chapman RA, Gautam SC (2001) Immunomodulatory activity of resveratrol: suppression of lymphocyte proliferation, development of cell-mediated cytotoxicity, and cytokine production. Biochem Pharmacol 62: 1299-1308. 
97. Holmes-McNary M, Baldwin AS Jr (2000) Chemopreventive properties of trans-resveratrol are associated with inhibition of activation of the lkappaB kinase. Cancer Res 60: 3477-3483.

98. Manna SK, Mukhopadhyay A, Aggarwal BB (2000) Resveratrol suppresses TNF-induced activation of nuclear transcription factors NF-kappa B, activator protein-1, and apoptosis: potential role of reactive oxygen intermediates and lipid peroxidation. J Immunol 164: 6509-6519.

99. Donnelly LE, Newton R, Kennedy GE, Fenwick PS, Leung RH, et al. (2004) Anti-inflammatory effects of resveratrol in lung epithelial cells: molecular mechanisms. Am J Physiol Lung Cell Mol Physiol 287: L774-L783.
100.Bi XL, Yang JY, Dong YX, Wang JM, Cui YH, et al. (2005) Resveratrol inhibits nitric oxide and TNF-alpha production by lipopolysaccharideactivated microglia. Int Immunopharmacol 5: 185-193.

101. Colín-González AL, Ali SF, Túnez I, Santamaría A (2015) On the antioxidant, neuroprotective and anti-inflammatory properties of S-allyl cysteine: An update. Neurochem Int 89: 83-91. 